\title{
Healthcare Delivery and Huntington's Disease During the Time of COVID-19
}

\author{
Anna C. Pfalzer ${ }^{\mathrm{a}, *}$, Lisa M. Hale ${ }^{\mathrm{a}}$, Elizabeth Huitz ${ }^{\mathrm{a}}$, Danielle A. Buchanan ${ }^{\mathrm{a}}$, Brittany K. Brown ${ }^{\mathrm{a}}$, \\ Sarah Moroz ${ }^{\mathrm{a}}$, Renee M. Rouleau ${ }^{\mathrm{a}}$, Kaitlyn R. Hay ${ }^{\mathrm{a}}$, Jennifer Hoadley ${ }^{\mathrm{a}}$, Amy Laird ${ }^{\mathrm{a}}$, \\ Abagail E. Ciriegio ${ }^{\mathrm{b}}$, Kelly H. Watson ${ }^{\mathrm{b}}$, Maile T. Jones ${ }^{\mathrm{b}}$, Ya-Chen Lin ${ }^{\mathrm{c}}$, Hakmook Kang ${ }^{\mathrm{c}}$, \\ Heather Riordan $^{\mathrm{a}}$, David A. Isaacs ${ }^{\mathrm{a}}$, Katherine E. McDonell ${ }^{\mathrm{a}}$, \\ Bruce E. Compas ${ }^{\mathrm{b}}$ and Daniel O. Claassen ${ }^{\mathrm{a}}$ \\ ${ }^{a}$ Department of Neurology, Vanderbilt University Medical Center, Nashville, TN, USA \\ ${ }^{\mathrm{b}}$ Department of Psychology and Human Development, Vanderbilt University Medical Center, Nashville, \\ TN, USA \\ ${ }^{\mathrm{c}}$ Department of Biostatistics, Vanderbilt University Medical Center, Nashville, TN, USA
}

Pre-press 19 April 2021

\begin{abstract}
.
Background: Safer-at-home orders during the COVID-19 pandemic altered the structure of clinical care for Huntington's disease (HD) patients. This shift provided an opportunity to identify limitations in the current healthcare infrastructure and how these may impact the health and well-being of persons with HD.

Objective: The study objectives were to assess the feasibility of remote healthcare delivery in HD patients, to identify socioeconomic factors which may explain differences in feasibility and to evaluate the impact of safer-at-home orders on HD patient stress levels.

Methods: This observational study of a clinical HD population during the 'safer-at-home' orders asked patients or caregivers about their current access to healthcare resources and patient stress levels. A chart review allowed for an assessment of socioeconomic status and characterization of HD severity.

Results: Two-hundred and twelve HD patients were contacted with 156 completing the survey. During safer-at-home orders, the majority of HD patients were able to obtain medications and see a physician; however, $25 \%$ of patients would not commit to regular telehealth visits, and less than 50\% utilized an online healthcare platform. We found that $37 \%$ of participants were divorced/single, $39 \%$ had less than a high school diploma, and nearly $20 \%$ were uninsured or on low-income health insurance. Patient stress levels correlated with disease burden.

Conclusion: A significant portion of HD participants were not willing to participate in telehealth services. Potential explanations for these limitations may include socioeconomic barriers and caregiving structure. These observations illustrate areas for clinical care improvement to address healthcare disparities in the HD community.
\end{abstract}

Keywords: Huntington's disease, telehealth, socioeconomic status, health disparities, stress

*Correspondence to: Anna C. Pfalzer, PhD, 1500 21st Avenue South, Suite 1532, Nashville, TN 37212, USA. Tel.: +1 615473 4472; E-mail: anna.c.pfalzer@vumc.org.

\section{INTRODUCTION}

The coronavirus disease 19 (COVID-19) pandemic has resulted in unique stressors for patients, caregivers and physicians, and altered the delivery of healthcare services. During the 'safer-at-home' orders, in-person clinical visits were restricted due 
to concerns of COVID-19 transmission. Many vulnerable adults noted greater isolation and lonliness. In response to the restrictions on in-person appointments, many clinics began adoption of telehealth visits $[1,2]$. However, there exist structural barriers that prevent universal adoption of telehealth, and access to specialty care. These include inconsistent access to internet services, limited technological literacy, and ineffective communication from clinicians to patients, [3, 4]. The care for Huntington's disease (HD) patients requires complex medication management and the need for an array of health care services unique to HD patients [5, 6]. For instance, HD patients seen in a multi-disciplinary clinic are often followed by several specialties including a neurologist, a psychiatrist, physical and occupational therapists, speech language pathologists, genetic counselors and social workers. Thus, the inability to interact with all of these providers may detrimentally impact patient health as well as place additional burdens on their caregivers.

To understand the prevalence of these potential barriers in patients with HD, we assessed the challenges to adapting to this new environment by reviewing medical care options with patients and caregivers during the safer-at-home orders. The Vanderbilt University Medical Center (VUMC) is a level 1 Huntington Disease Society of America (HDSA) Center of Excellence (COE), and provides care for patients who live in the middle Tennessee region. The breadth of this coverage includes Illinois, Kentucky, Alabama, North Carolina, South Carolina, Georgia, and Mississippi.

The purpose of this study was three-fold: 1) identify the feasibility of remote healthcare and the delivery of healthcare services, 2) identify geographic or socioeconomic barriers which might impact accessibility to healthcare services and 3) evaluate patient stress levels during the safer-at home time period. While HD is a rare disease, insights from this cohort should inform wider patient populations and define opportunities for improvement in reducing healthcare disparities.

\section{MATERIALS AND METHODS}

All patients with a clinical diagnosis of HD who are currently receiving care at the VUMC HDSA COE were contacted via phone during 'safer-athome' orders between April and May 2020. The primary purpose of this contact was to identify limitations in remote healthcare delivery and thereby identify additional clinical support needs, identify potential socioeconomic variables which may contribute to limitations in remote healthcare delivery and determine patient perceived stress levels during a time of social isolation. Clinicians and staff within the COE completed phone interviews with either the HD patient or their caregiver: caregivers completed surveys on behalf of the patient when they were unwilling or unable to participate. Our survey included questions relating to current clinical needs, economic hardship and perceived levels of stress as a result of the COVID-19 pandemic as shown in Table 1 . In total, the survey contained 20 questions: 2 questions regarding the survey participant and their relationship to the patient (if appropriate), 2 multiplechoice questions regarding patient sex and race, 1 open-ended question for patient age, five yes/no questions relating to the patients ability to receive healthcare and the appropriate resources as well as whether they are experiencing economic hardship due to the on-going pandemic.

Participants completed the 10-question Perceived Stress Scale (PSS), a widely used instrument designed to assess self-reported and caregiver-reported levels of psychological stress [7, 8]. The PSS measures the degree to which situations in a participants life are appraised as stressful as well as how unpredictable, uncontrollable, and overloaded each participant feels in their life. For each item, participants indicate how often $(0=$ never to $4=$ very often $)$ they have thought or felt a certain way in the past month. Total score (PSS total score) is the sum of the individual item scores, yielding a total score range of $0-40$.

In addition to these survey questions, we documented select clinical and demographic variables, in order to consider other potential impediments to care delivery. We included patient marital status, highest education level completed, health insurance status, online health portal access, and county and state of residence. The online health portal refers to the "MyHealth" at Vanderbilt platform which provides patients greater access to their medical records and facilitates patient-provider communication via telemedicine. Utilization of this platform is dependent upon internet access and required for telehealth.

We also included clinical indicators of disease status such as pathogenic allele size (CAG), CAGAge-related Product (CAP)-score, and total functional capacity (TFC) as depicted in Table 2. CAP-score is an indicator of cumulative exposure to 
Table 1

Telephone survey administered to HD patients or caregivers

\begin{tabular}{|c|c|}
\hline Questions & Responses \\
\hline Who are you speaking with? & $\begin{array}{l}\circ \text { Patient } \\
\circ \text { Caregiver }\end{array}$ \\
\hline Caregiver's relationship to patient & 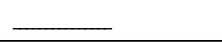 \\
\hline Patient's age & $\underline{-}$ \\
\hline Patient's gender & $\begin{array}{l}\circ \text { Male } \\
\circ \text { female }\end{array}$ \\
\hline Patient's race & $\begin{array}{l}\circ \text { Caucasian } \\
\circ \text { American-Black } \\
\circ \text { Hispano/ Latino } \\
\circ \text { Other } \\
\end{array}$ \\
\hline Are you able to see or get in contact with a physician? & $\begin{array}{l}\circ \mathrm{No} \\
\circ \text { Yes }\end{array}$ \\
\hline Are you able to get your medications? & $\begin{array}{l}\circ \mathrm{No} \\
\circ \mathrm{Yes} \\
\end{array}$ \\
\hline Are you able to plan on regular telehealth contacts? & $\begin{array}{l}\circ \text { No } \\
\circ \text { Yes } \\
\end{array}$ \\
\hline Are you interested in participating in our monthly support group? & $\begin{array}{l}\circ \mathrm{No} \\
\circ \mathrm{Yes} \\
\end{array}$ \\
\hline Are you experiencing economic hardships? & $\begin{array}{l}\circ \text { No } \\
\circ \text { Yes }\end{array}$ \\
\hline $\begin{array}{l}\text { Now I would like to ask you some questions about your recent } \\
\text { stress levels and how you have been feeling. For each question, } \\
\text { please answer on a scale from } 0-4 \text { where } 0=\text { never, } 1=\text { almost never, } \\
2=\text { sometimes, } 3 \text { = fairly often and } 4=\text { very often. In the last month... }\end{array}$ & $\begin{array}{l}\circ 0=\text { never } \\
\circ 1=\text { almost never } \\
\circ 2=\text { sometimes } \\
\circ 3=\text { fairly often } \\
\circ 4=\text { very often }\end{array}$ \\
\hline $\begin{array}{l}\text { How often have you been upset because of something that happened unex } \\
\text { How often have you felt that you were unable to control the important thi } \\
\text { How often have you felt nervous or "stressed" } \\
\text { How often have you felt confident about your ability to handle your perso } \\
\text { How often have you felt that things were going your way? } \\
\text { How often have you found that you could not cope with all the things that } \\
\text { How often have you been able to control irritations in your life? } \\
\text { How often have you felt that you were on top of things? } \\
\text { How often have you felt angered because of things outside of your contro } \\
\text { How often have you felt difficulties were piling up so high that you could }\end{array}$ & $\begin{array}{l}\text { y? } \\
\text { blems life? } \\
\text { d to do? }\end{array}$ \\
\hline
\end{tabular}

mutant Huntingtin and is calculated using the following equation: number of CAG repeats -33.66 / Age [9]. TFC is a standardized assessment to determine an individual's capacity to carry out activities of daily living, work, manage finances and live independently [10]. TFC scale ranges from 13 (no impairments) to 0 (severe impairments) [10]. Patients highest completed education was recorded as 7th-9th grade, 10th-12th grade, some college, Associate degree, Bachelor degree, or Graduate degree. These grades and degrees correspond to 7-9 years, 10-12 years, 12-14 years, 14 years, 16 years, and $16+$ years of formal education. Tableau software was used to generate a regional distribution of our survey participant responses (Tableau, version 2019.4, Seattle, WA). We utilized United States Census data from 2010-2019 to determine participant "residence type" based upon the number of inhabitants by county: rural $(0-10,000)$, village $(10,001-50,000)$, town $(50,001-100,000)$, or city $(100,001+)$ [11]. We categorized education level and residence type to match those utilized by the Enroll-HD database.

\section{Data analyses}

We compared patient versus caregiver survey responses as well as clinical demographics to identify any significant difference in responses in these variables using Man-Whitney tests for nonparametric data. We found that participant responses significantly varied only by CAG repeat, CAP-score, and TFC. We found no differences in responses re- 
Table 2

Demographic and clinical information from participant medical records. Education level refers to the patients highest completed education level; residence type is based upon the number of occupants within a county as reported by the US Census Bureau

\begin{tabular}{|c|c|}
\hline Pathogenic allele CAG length & $\underline{-}$ \\
\hline Total functional capacity & $\underline{-}$ \\
\hline Marital status & $\begin{array}{l}\circ \text { Single/partnered } \\
\circ \text { Married } \\
\circ \text { Divorced/separated } \\
\circ \text { Widowed } \\
\end{array}$ \\
\hline Education level & $\begin{array}{l}\circ \text { 7th-9th grade } \\
\circ \text { 10th-12th grade } \\
\circ \text { Associate degree } \\
\circ \text { Bachelor degree } \\
\circ \text { Graduate degree }\end{array}$ \\
\hline Online health portal access & $\begin{array}{l}\circ \text { Not activated } \\
\circ \text { Activated }\end{array}$ \\
\hline Health insurance provider & $\begin{array}{l}\circ \text { Uninsured } \\
\circ \text { Medicaid } \\
\circ \text { Medicare } \\
\circ \text { Private } \\
\end{array}$ \\
\hline County of residence & $\underline{ }$ \\
\hline State of residence & 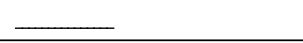 \\
\hline Residence type & $\begin{array}{l}\circ \text { Rural }(0-10,000) \\
\circ \text { Village }(10,001-20,000) \\
\circ \text { Town }(20,001-50,000) \\
\circ \text { City }(50,000+)\end{array}$ \\
\hline
\end{tabular}

lating to clinical needs, stress levels, access to healthcare services or demographic variables relating to socioeconomic status as determined by Chi-square or logistic regression. As such, participant responses are reported separately (patient-reported vs caregiverreported) for CAG repeat, CAP-score, and TFC and combined (all participants) for the remaining outcomes. The mean value for PSS total score and CAP-score were imputed for 5 missing PSS values and 9 missing CAP-scores.

Socioeconomic profile for participants was determined using highest education level completed, marital status, health insurance provider, and residence setting based upon county population. Profiles within each variable are depicted using pie-charts with the percentage of participants. We also determined the percentage of respondents who were experiencing economic hardship (yes/no) as a result of the pandemic.

We report the percentage of participants who are able to: i) see a physician, ii) obtain their medication, iii) participate in telehealth visits, iv) utilize online health platform, and v) participate in online support groups. In order to determine what factors might impact a patients ability to receive necessary healthcare services, we examined the association between a patients ability to do telehealth and utilize online health platforms with residence setting, type of health insurance coverage and recent economic hardship using multiple logistic regressions.

We evaluated perceived stress levels both through patient report as well as caregiver report on behalf of the patient [8]. The association between patient stress levels and patient CAG and CAP-score as well as ability to receive necessary healthcare services were examined using Spearman correlation and logistic regression. Similarly, we also evaluated how economic hardship impacted stress levels in HD patients using logistic regression.

\section{Ethics}

This study was approved by Vanderbilt University Medical Center Institutional Review Board. Consent for this study was provided over the telephone prior to administration of the telephone survey.

\section{RESULTS \\ Participant demographics}

Two-hundred and twelve HD patients were contacted and 156 participants completed the survey for a response rate of $74 \%$. Participants completing the survey reside primarily within Tennessee, North Carolina, South Carolina, Georgia, Mississippi, Illinois, Kentucky, Alabama, and Florida as displayed in Fig. 1. Of those participants, 82 were patients and 74 were caregivers. The profile of our caregiver respondents were $60 \%$ spouses, $21 \%$ parents, $10 \%$ offspring, and $9 \%$ either in-laws or grandparents.

\section{Patient clinical demographics}

The patients completing the survey were $44 \%$ male, with $96.6 \%$ identifying as Caucasian, $2.8 \%$ as Hispanic or Latino, $1.7 \%$ as African-American, and $0.6 \%$ as North African. Surveys completed by patients represented a cohort with a significantly lower average CAG-repeat and CAP-score and higher TFC $(p<0.05)$ in comparison to surveys completed by caregivers as shown in Table 3. More specifically, patient-reported average $C A G$ repeat length was 43.5 $( \pm 3.4)$, average CAP-score was $442.7( \pm 137.7)$ and average TFC of $9.7( \pm 3.5)$ while caregivers completed surveys on behalf of patients with an average CAP-repeat length of $45.0( \pm 5.2)$, CAP-score of $536.2( \pm 109.0)$ and TFC of $7.8( \pm 3.8)$ (Table 3$)$. 


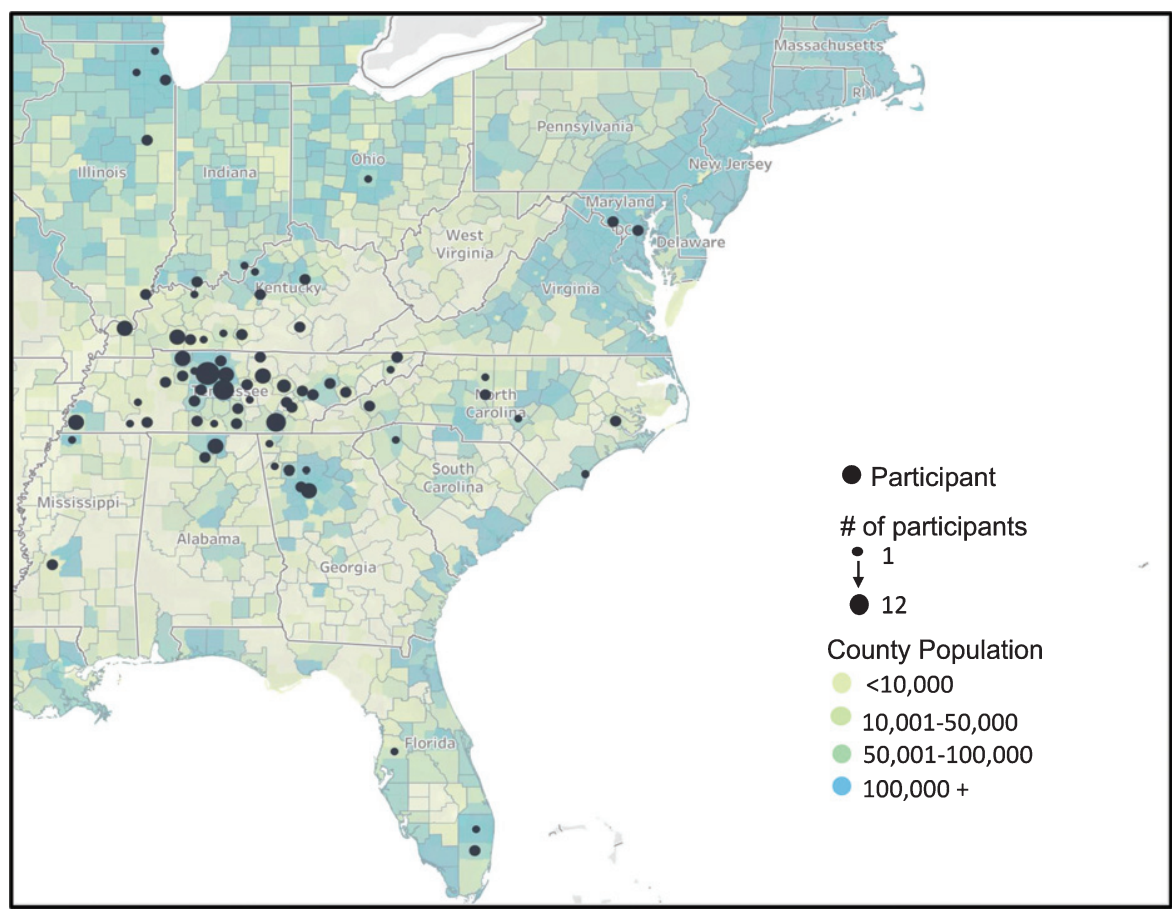

Fig. 1. Regional distribution of survey participants throughout the United States. Each dot indicates a participant with increasing dot size representative of multiple participants from that county. County population is based upon the 2018 US Census Bureau data with increasing population illustrated through increasing blue color tone.

Table 3

Participant demographics based upon patient self reports and caregiver reports on behalf of patients. CAG refers to the number of pathogenic repeats within the Huntingtin gene; CAP-score refers to the CAG-Age related Product and TFC refers to Total Functional Capacity. Participant profile (patient- vs caregiver reports) and patient sex are shown as percentages; patient age, CAG, CAP-score, and TFC are all reported as mean \pm S.D with corresponding $p$-value

\begin{tabular}{lccc}
\hline Participant & Patient-reported & Caregiver-reported & $p$ \\
\hline Participants (\%) & $82(52.6)$ & $74(47.4)$ & N/A \\
Patient sex (\% male) & 40.2 & 50.0 & $p=0.08$ \\
Patient age (y \pm S.D.) & $47.9 \pm 14.0$ & $51.0 \pm 15.0$ & $p=0.11$ \\
Patient CAG ( \pm S.D.) & $43.5 \pm 3.4$ & $45.0 \pm 5.2$ & $p=0.04$ \\
Patient CAP-score $( \pm$ S.D.) & $442.7 \pm 137.7$ & $536.2 \pm 109.0$ & $p<0.001$ \\
Patient TFC $( \pm$ S.D.) & $9.7 \pm 3.5$ & $7.8 \pm 3.8$ & $p=0.001$ \\
\hline
\end{tabular}

\section{Socioeconomic profile of HD patients}

Of the 156 respondents, there were $9 \%$ uninsured, $9 \%$ with medicaid, $32 \%$ with medicare, and $50 \%$ with commercial health insurance (Fig. 2). At the time of our study, twenty-two percent of patients were single, $15 \%$ were either divorced or separated, $61 \%$ were married or in a partnership, and $2 \%$ were widows. The highest completed education level for patients indicates that $6 \%$ of patients completed 7th-9th grade, $33 \%$ completed 10th-12th grade, $16 \%$ completed some college whereas $31 \%$ have an Associate degree. Ten percent of HD patients have a Bachelor degree and $4 \%$ have a graduate degree (Fig. 2A). Lastly,
$22 \%$ of patients live in a rural area (less than 10,000 occupants), $6 \%$ in a village (10,-50,000 occupants), $34 \%$ in a town $(50-100,000)$, and $38 \%$ live in a city of more than 100,000 occupants (Fig. 2D). The telephone survey question relating to economic hardship among participants found that $29 \%$ of patients endorced experiencing economic hardship.

\section{Feasibility of remote healthcare delivery}

Our survey included 5 'yes/no' questions directly related to the feasibility of remote healthcare and the delivery of healthcare services during COVID-19 'safer-at-home' orders on HD patients. Eighty-seven 


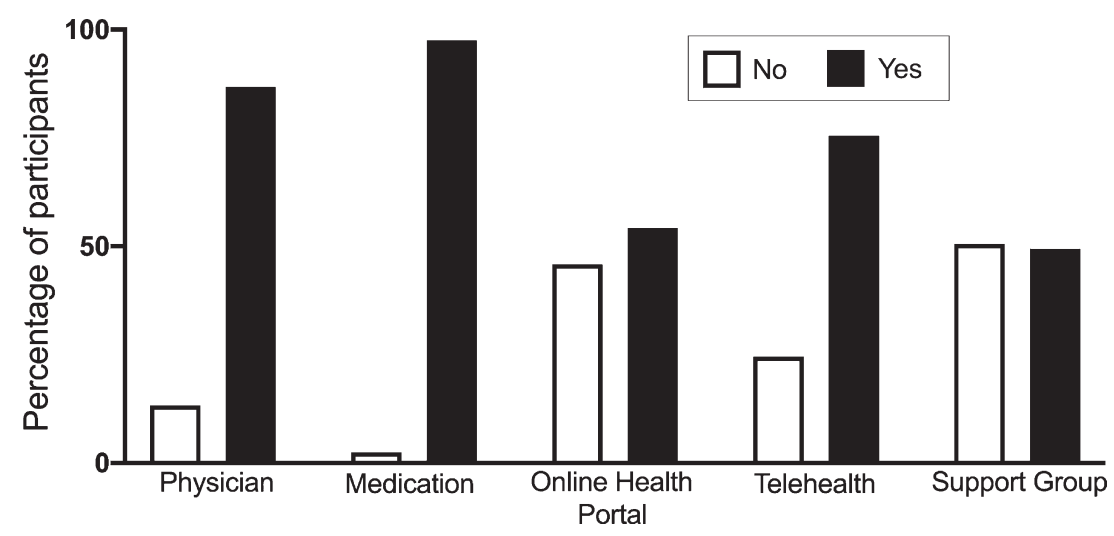

Fig. 2. Feasibility of remote healthcare delivery in HD patients. Participants were asked about their ability to see a physician (Physician), obtain medication (Medication), communicate with medical providers using online health platform (Online Health Portal), ability to participate in telehealth visits (Telehealth) and online support groups (Support group). Data is shown as percentage of all participants endorsing yes or no.

\section{A Education level}

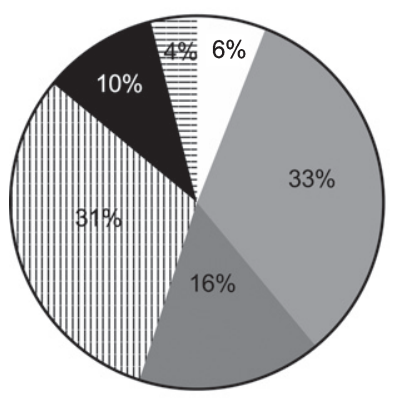

C Health insurance

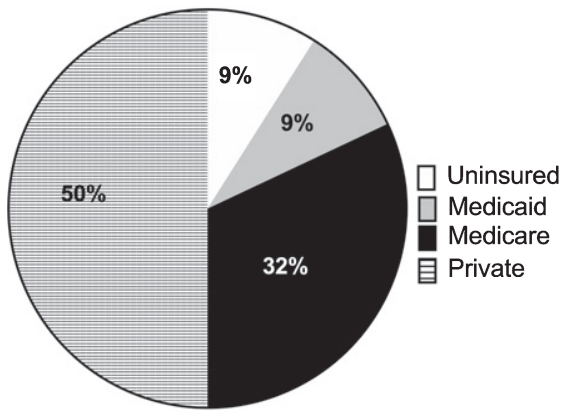

B Marital status
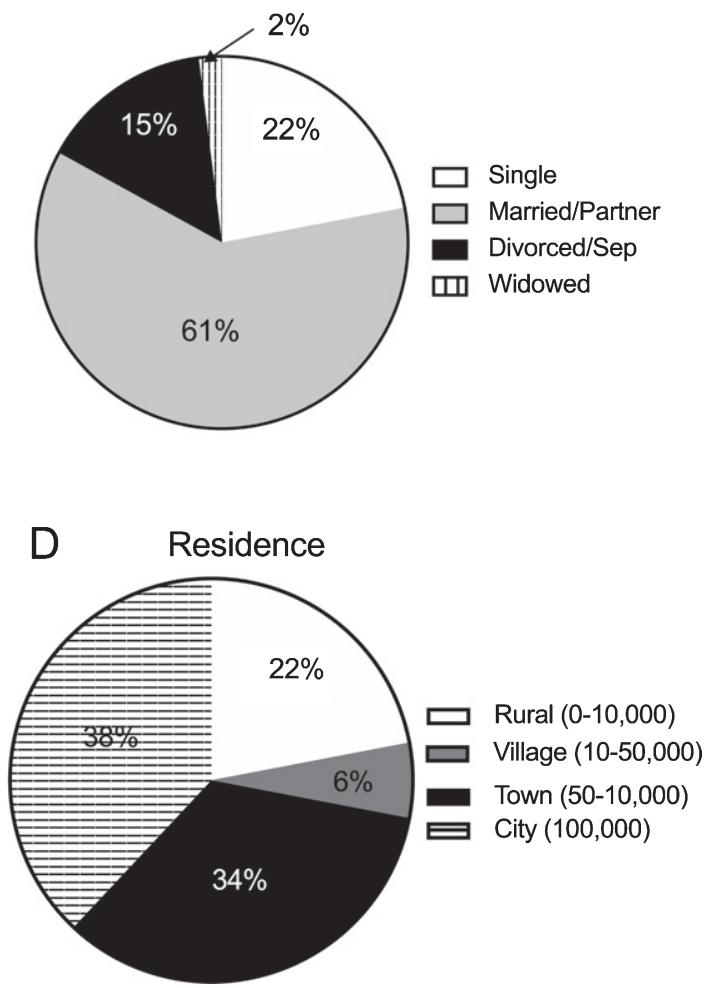

Fig. 3. Socioeconomic demographics for HD patients completing the survey. We report A) highest education level completed, B) marital status, C) health insurance provider, and D) residence type by county population. Percentages within each pie chart indicates the percent of all participants which fall within the respective category.

percent of participants indicated that the patient was able to get an appointment with a physician and $98 \%$ were able to receive necessary medication (Fig. 3). Fifty-four percent of patients represented had active online health portal accounts and $75 \%$ were able to participate in telehealth appointments (Fig. 3). Approximately $50 \%$ of respondents expressed an interest in participating in online support groups (Fig. 3).

\section{Perceived stress levels}

We examined patient stress levels using patient self reports and caregiver reports on behalf of patients. 
We found that patients tended to report lower perceived stress scores (PSS) $(14.46 \pm 8.3)$ compared to caregiver reports on behalf of patients (16.2 \pm 7.3 ; $p=0.11$ ) (Fig. 4A). Given that caregiver respondents reported on patients with significantly greater disease burden, we assessed the association between PSS and CAP-score and TFC. There was a non-significant negative correlation $(\mathrm{r}=-0.19 ; p=0.06)$ between patient reported stress score (Fig. 4B), whereas there was no relationship between caregiver-reported patient stress and patient CAP-score (Fig. 4C). There was no relationship between PSS score and TFC.

\section{DISCUSSION}

The safer-at home response to the COVID-19 pandemic was adopted in many regions across the United

\section{A \\ Perceived Stress Levels}

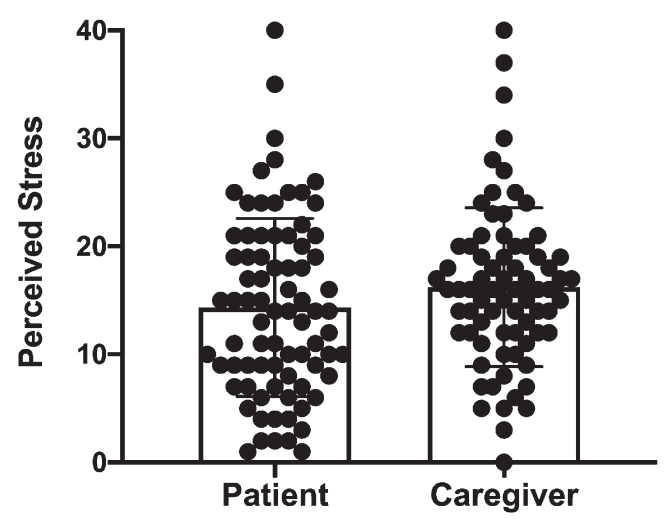

\section{Caregiver-reported Patient Stress}

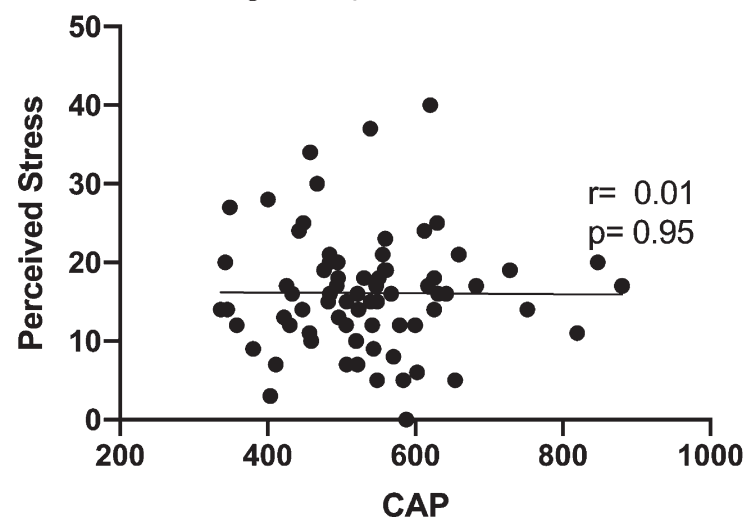

States, although duration varied. Safer-at home orders resulted in unique challenges to both healthcare providers, healthcare delivery, and patients. Our findings provide several important insights into the feasibility of remote health care delivery and socioeconomic factors which may impact assessibility to these necessary healthcare services. Although some healthcare services are unique to HD, we believe these findings are likely emblematic of current healthcare needs across other neurodegenerative diseases.

Our survey identified several possible limitations in remote healthcare and the delivery of health services for HD patients. We found that nearly $50 \%$ of patients did not actively utilize the online healthcare platform-which facilitates communication between healthcare providers and patients. Additionally, approximately $25 \%$ of patients were unable to participate in regular telehealth visits. It is unclear

\section{B Patient-reported Stress}

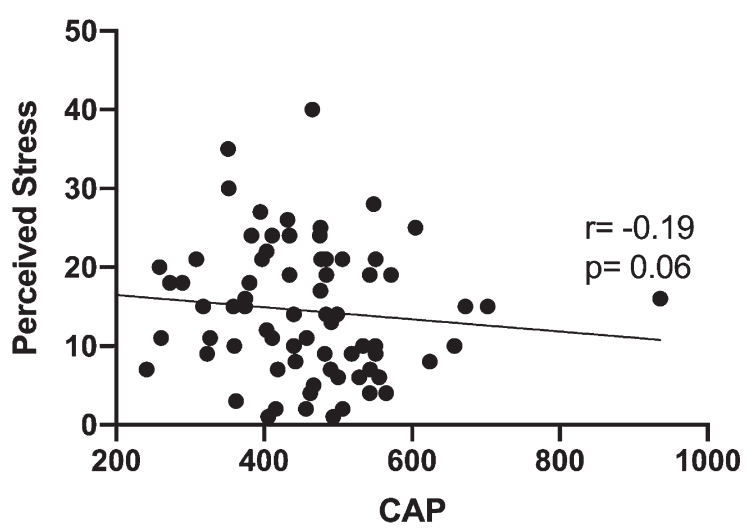

Fig. 4. Stress levels in patients. A) Perceived stress levels reported by patients and caregivers (on behalf of patients), B) association between patient CAP-score and patient reported perceived stress, C) association between patient CAP-score and caregiver-reported patient stress. Data are reported as Spearman's $r$ and corresponding $p$-value. 
based on our data whether inability to participate is due to unwillingness (would prefer in-person visits), inability (lack of internet access), or economic barriers (cost concerns); however, it is clear that a system based entirely on telehealth may neglect a quarter of this HD patient population. Future studies examining clinical care needs should explore ways to increase access of telehealth services in HD. We also found that approximately $50 \%$ of patients would participate in a monthly online support group facilitated by our social work team. This percentage represents a substantial increase from current in-person participation and may reflect patients desire for additional social support resources. One clear benefit of virtual support meetings relates to the ability to bridge geographic barriers and provide HD families across the region an opportunity to connect with the broader HD community [12]. This benefit is particularly relevant for our HD population as Fig. 1 demonstrates our participants travel considerable distances to receive care as well as live in rural areas with potentially limited access to health and internet services. Furthermore, these support groups can be used as educational platforms to provide HD families with skills to cope with unique stressors and challenges exacerbated by the pandemic.

To better articulate underlying causes of limitations in healthcare accessibility, we examined variables associated with socioeconomic status including: highest completed education, marital status, residential setting and health insurance provider. We found that nearly $40 \%$ of our patients had a high school degree or less, which is equivalent to less than 12 years of formal education. This finding is important, given recent studies like Tabrizi et al, where participants have on average 16 years of formal education [13]. These results emphasize the need to enroll patients with diverse ethnic, health literacy, and educational background [14].

Our survey also demonstrates that approximately $20 \%$ of our patients are either uninsured or have Medicaid-a federal health insurance program for individuals with low income. Recent work on variations in health care coverage for federal programs as well as anecdotal evidence from medical providers reveals that access to necessary health care services and long-term care accommodations is more difficult to acquire for those uninsured or on Medicaid [15]. One potential resource for uninsured patients would be the adoption of the Huntington's Disease Parity Act of 2019 which waives the current requirement of a 24-month waiting period for individuals with an HD diagnosis to receive Medicare. Adoption of the current bill would eliminate a significant barrier to health services by allowing previously uninsured patients to receive proper multi-disciplinary care upon diagnosis. Recent trends in HD clinical research to target earlier stages of disease suggests that earlier interventions may yield the greatest chances of delaying disease progression [16-19]. As such, reducing the number of uninsured or Medicaid-sponsored patients and thereby improving access to specialized equipment and clinical care, could ultimately change the disease trajectory for those individuals as well as reduce economic and emotional hardship on caregivers.

Another unique challenge for these participants relates to the high rate of divorce or singledom. This presents several challenges as unmarried patients have a single source of income and have no immediate caregiver. In fact, over $20 \%$ of caregiver respondents in our survey were parents of the affected patient and nearly $10 \%$ were offspring. This caregiver profile mirrors a previous study of HD caregivers although nearly $25 \%$ of caregivers in that sample were children [20]. This caregiver profile emphasizes the types of resources that may be useful to HD patients and their families. For instance, young adults in the caregiver role may benefit from additional resources regarding long-term care for their parent as well as the possibility to utilize the federal medical leave act (FMLA) to care for an ailing family member. Additionally, biological offspring have a $50 \%$ chance of inheriting the huntingtin gene mutation and developing HD. Most of these caregivers have the burden of caring for a sick parent, as well as addressing their at-risk genetic status or recent HD diagnosis. These individuals face a unique set of challenges which require more personalized attention from healthcare providers, including encouragement to maintain their own mental and physical health. A clear limitation of our study is the lack of information regarding the health and well-being of our caregiver respondents. Future work in this population will include a more thorough examination of caregiver needs.

Lastly, we wanted to understand how these limitations in healthcare assessibility and socioeconomic challenges impacted stress in patients. We report stress levels as patient self-reported stress as well as caregiver perceived patient stress. Although we are unable to compare pre-COVID perceived stress levels for our respondents, a recent report found that pre-COVID stress levels increased approximately 3 - 
fold amid COVID in health US adults between 30-54 years of age [21]. While we did not find any significant difference between patient perceived stress and those stress levels reported by caregivers (on behalf of patients), we did find that patient stress levels decrease with increasing disease burden. Specifically, we observed a non-significant $(p=0.06)$ negative correlation between patient perceived stress and patient CAP-score (lower stress with greater disease burden); whereas there was no relationship between caregiver perceived patient stress and patient CAP-score. For patients, this finding may be indicative of cognitive changes that protect against stress. Although the cause of increased stress in patients remains unknown, it is clear that emotional and physiological stress exert detrimental effects on mental [22, 23] and physical health [24] as well as neuronal health $[25,26]$. Increased stress impairs aspects of cognitive functioning [27] and thus identifying the causes of stress are particularly important in HD since cognitive decline is an inherent manifestation of disease. In fact, we recently described a direct connection between anxiety and depression and working memory in HD offspring [28]. Perhaps more importantly, they suggest that skills to manage and cope with stress may be an effective intervention to prevent or delay cognitive impairments in HD [28].

Overall this work demonstrates the importance of developing universal clinical care protocols for HD that reflect the diverse needs of this population. Safter-at-home orders due to the COVID-19 pandemic provided a unique opportunity to more clearly identify health care disparities in a disease population with significant economic vulnerability. It illustrates that remote telehealth care and online healthcare systems may not be immeditately adopted by a substantial portion of HD patients and that nearly a quarter of HD patients could benefit from increased access to healthcare services through Medicare coverage. These findings emphasize many opportunities for improved health care delivery for a diverse population.

\section{ACKNOWLEDGMENTS}

The work presented here was supported by the VUMC Huntington Disease Society of America Center of Excellence. We acknowledge all our Huntington Disease families who teach us resilience and give us hope.

\section{CONFLICT OF INTEREST}

ACP, LMH, EH, DAB, BKB, SM, RMR, KRH, JH, AL, AEC, KHW, MTJ, YL, HK, HR, DAI, KM, BEC and DOC declare no conflicts of interest relevant to the work included in this manuscript.

\section{REFERENCES}

[1] Bloem BR, Dorsey ER, Okun MS. The coronavirus disease 2019 crisis as catalyst for telemedicine for chronic neurological disorders. JAMA Neurol. 2020;77:927-8.

[2] Kasab S Al, Almallouhi E, Holmstedt CA. Opinion: Optimizing the use of teleneurology during the COVID-19 pandemic. Telemed J E Health. 2020;26(10):1197-8.

[3] Orlando JF, Beard M, Kumar S. Systematic review of patient and caregivers' satisfaction with telehealth videoconferencing as a mode of service delivery in managing patients' health. PLoS One. 2019;14(8):e0221848.

[4] Scott Kruse C, Karem P, Shifflett K, Vegi L, Ravi K, Brooks M. Evaluating barriers to adopting telemedicine worldwide: A systematic review. J Telemed Telecare. 2018;24(1):4-12.

[5] Roos RAC. Huntington's disease: A clinical review. Orphanet J Rare Dis. 2010;5:40.

[6] Mestre TA, Shannon K. Huntington disease care: From the past to the present, to the future. Parkinsonism Relat Disord. 2017;44:114-8

[7] Cohen S, Kamarck T, Mermelstein R. A global measure of perceived stress. J Health Soc Behav. 1983;24(4):385-96.

[8] Weckesser LJ, Dietz F, Schmidt K, Grass J, Kirschbaum C, Miller R. The psychometric properties and temporal dynamics of subjective stress, retrospectively assessed by different informants and questionnaires, and hair cortisol concentrations. Sci Rep. 2019;9(1):1098.

[9] Zhang Y, Long JD, Mills JA, Warner JH, Lu W, Paulsen JS. Indexing disease progression at study entry with individuals at-risk for Huntington disease. Am J Med Genet Part B Neuropsychiatr Genet. 2011;156(7):751-63.

[10] Shoulson I, Fahn S. Huntington disease: Clinical care and evaluation. Neurology. 1979;29(1):1-3.

[11] US Census Bureau. County Population by Characteristics: 2010-2019.

[12] Sands RG. Social work with victims of huntington's disease. Soc Work Health Care. 1984;9(4):63-71.

[13] Scahill RI, Zeun P, Osborne-Crowley K, Johnson EB, Gregory S, Parker C, et al. Biological and clinical characteristics of gene carriers far from predicted onset in the Huntington's disease Young Adult Study (HD-YAS): A cross-sectional analysis. Lancet Neurol. 2020;19(6):502-12.

[14] Clark LT, Watkins L, Piña IL, Elmer M, Akinboboye $\mathrm{O}$, Gorham $\mathrm{M}$, et al. Increasing diversity in clinical trials: Overcoming critical barriers. Curr Probl Cardiol. 2019;44(5):148-72.

[15] Thompson FJ, Cantor JC, Farnham J. Medicaid long-term care: State variation and the intergovernmental lobby. J Health Polit Policy Law. 2016;41(4):763-80.

[16] Thompson JA, Cruickshank TM, Penailillo LE, Lee JW, Newton RU, Barker RA, et al. The effects of multidisciplinary rehabilitation in patients with early-tomiddle-stage Huntington's disease: A pilot study. Eur J Neurol. 2013;20(9):1325-9.

[17] Zinzi P, Salmaso D, De Grandis R, Graziani G, Maceroni $\mathrm{S}$, Bentivoglio A, et al. Effects of an intensive rehabilitation 
programme on patients with Huntington's disease: A pilot study. Clin Rehabil. 2007;21(7):603-13.

[18] Kempnich CL, Wong D, Georgiou-Karistianis N, Stout JC. Feasibility and efficacy of brief computerized training to improve emotion recognition in premanifest and earlysymptomatic Huntington's disease. J Int Neuropsychol Soc. 2017;23(4):314-21.

[19] Piira A, van Walsem MR, Mikalsen G, Nilsen KH, Knutsen S, Frich JC. Effects of a one year intensive multidisciplinary rehabilitation program for patients with Huntington's disease: A prospective intervention study. PLoS Curr. 2013;5:ecurrents.hd.9504af71e0d1f87830c2 5c394be47027

[20] Røthing M, Malterud K, Frich JC. Caregiver roles in families affected by Huntington's disease: A qualitative interview study. Scand J Caring Sci. 2014;28(4):700-5.

[21] McGinty EE, Presskreischer R, Han H, Barry CL. Psychological distress and loneliness reported by US Adults in 2018 and April 2020. JAMA. 2020;324:93-4.

[22] Penninx BWJH, Beekman ATF, Bandinelli S, Corsi AM, Bremmer M, Hoogendijk WJ, et al. Late-life depressive symptoms are associated with both hyperactivity and hypoactivity of the hypothalamo-pituitary-adrenal axis. Am J Geriatr Psychiatry. 2007;15(6):522-9.
[23] Hinkelmann K, Moritz S, Botzenhardt J, Riedesel K, Wiedemann K, Kellner M, et al. Cognitive impairment in major depression: Association with salivary cortisol. Biol Psychiatry. 2009;66(9):879-85.

[24] Rano J, Fridén C, Eek F. Effects of acute psychological stress on athletic performance in elite male swimmers. J Sports Med Phys Fitness. 2019;59(6):1068-76.

[25] Black CN, Bot M, Révész D, Scheffer PG, Penninx B. The association between three major physiological stress systems and oxidative DNA and lipid damage. Psychoneuroendocrinology. 2017;80:56-66.

[26] Flaherty RL, Owen M, Fagan-Murphy A, Intabli H, Healy $\mathrm{D}$, Patel A, et al. Glucocorticoids induce production of reactive oxygen species/reactive nitrogen species and DNA damage through an iNOS mediated pathway in breast cancer. Breast Cancer Res. 2017;19(1):35.

[27] McEwen BS, Sapolsky RM. Stress and cognitive function. Curr Opin Neurobiol. 1995;5(2):205-16.

[28] Ciriegio AE, Pfalzer AC, Hale L, McDonell KE, Claassen DO, Compas BE. Investigating the interplay of working memory, affective symptoms, and coping with stress in offspring of parents with Huntington's disease. Neuropsychology. 2020; doi: 10.1037/neu0000692 